\title{
High-Sensitivity pH Sensor Based on Coplanar Gate AlGaN/GaN Metal-Oxide-Semiconductor High Electron Mobility Transistor
}

\author{
Seong-Kun Cho $\mathbb{D}$ and Won-Ju Cho* *(D) \\ Department of Electronic Materials Engineering, Kwangwoon University, 20 Gwangun-ro, Nowon-gu, \\ Seoul 01897, Korea; whtjdrms98@gmail.com \\ * Correspondence: chowj@kw.ac.kr; Tel.: +82-2-940-5163
}

Citation: Cho, S.-K.; Cho, W.-J. High-Sensitivity $\mathrm{pH}$ Sensor Based on Coplanar Gate AlGaN/GaN Metal-Oxide-Semiconductor High Electron Mobility Transistor. Chemosensors 2021, 9, 42. https://doi.org/10.3390/ chemosensors 9030042

Academic Editor: Pietro Salvo

Received: 28 January 2021

Accepted: 24 February 2021

Published: 25 February 2021

Publisher's Note: MDPI stays neutral with regard to jurisdictional claims in published maps and institutional affiliations.

Copyright: (c) 2021 by the authors. Licensee MDPI, Basel, Switzerland. This article is an open access article distributed under the terms and conditions of the Creative Commons Attribution (CC BY) license (https:/ / creativecommons.org/licenses/by/ $4.0 /)$.

\begin{abstract}
The sensitivity of conventional ion-sensitive field-effect transistors is limited to the Nernst limit $(59.14 \mathrm{mV} / \mathrm{pH})$. In this study, we developed a $\mathrm{pH}$ sensor platform based on a coplanar gate AlGaN/GaN metal-oxide-semiconductor (MOS) high electron mobility transistor (HEMT) using the resistive coupling effect to overcome the Nernst limit. For resistive coupling, a coplanar gate comprising a control gate (CG) and a sensing gate (SG) was designed. We investigated the amplification of the $\mathrm{pH}$ sensitivity with the change in the magnitude of a resistance connected in series to each CG and SG via Silvaco TCAD simulations. In addition, a disposable extended gate was applied as a cost-effective sensor platform that helped prevent damages due to direct exposure of the AlGaN/GaN MOS HEMT to chemical solutions. The $\mathrm{pH}$ sensor based on the coplanar gate AlGaN/GaN MOS HEMT exhibited a pH sensitivity considerably higher than the Nernst limit, dependent on the ratio of the series resistance connected to the CG and SG, as well as excellent reliability and stability with non-ideal behavior. The $\mathrm{pH}$ sensor developed in this study is expected to be readily integrated with wide transmission bandwidth, high temperature, and high-power electronics as a highly sensitive biosensor platform.
\end{abstract}

Keywords: AlGaN/GaN MOS HEMT; coplanar gate; resistive coupling; $\mathrm{pH}$ sensor

\section{Introduction}

Developments in big data, artificial intelligence, deep learning, and internet of things in the fourth industrial revolution have led to increased human-machine interactions and, consequently, the requirement of the miniaturization and functionalization of electronic devices. In particular, biosensors are being actively studied as a core technology for human-machine interactions. Field-effect transistor (FET)-based biosensors offer various advantageous properties, including a short response time and accurate detection, and they can be mass produced and miniaturized [1,2]. However, conventional ion-sensitive FETs (ISFETs) have a sensitivity limit of $59.14 \mathrm{mV} / \mathrm{pH}$, called the Nernst limit, which hinders their commercialization $[3,4]$. Double gate structure ISFETs based on silicon-on-insulator are drawing attention because they can overcome the Nernst limit via asymmetric capacitive coupling of the upper and lower gate oxides [5-8]. In addition, in our previous work, we studied a silicon-based device that amplifies the sensitivity through capacitive coupling between the coplanar gate and the floating gate, and here we investigated the capacitive coupling effect according to the coplanar gate area and the corresponding sensitivity amplification [9]. However, owing to the limitations of the physical characteristics of silicon, these transistors cannot easily be integrated with wide transmission bandwidths and at high temperatures. Meanwhile, compound semiconductor-based AlGaN/GaN high electron mobility transistors (HEMTs) exhibit low on-resistance and rapid switching speeds owing to the high-mobility two-dimensional electron gas induced by the discontinuity of the conduction band in the AlGaN/GaN heterostructure and its piezoelectric polarization [10]. In addition, AlGaN/GaN HEMT-based sensors have shown potential for application for the detection of DNA, antigens, glucose, cellular responses, and gas; further, these sensors 
can be monolithically integrated with signal processing and amplification circuits or radio frequency $(\mathrm{RF})$ signal transmission circuits, which are convenient for reading data and receiving remote signals [11-18]. Nevertheless, the leakage current of AlGaN/GaN HEMTs due to the trap-assisted tunneling and surface state is crucial. In order to attain low power consumption and high conversion efficiency, high breakdown voltage, leakage suppression, and high on/off current ratio are crucial. Meanwhile, the metal-oxide-semiconductor (MOS) structure can achieve a high breakdown voltage and on/off current ratio because the gate insulator effectively prevents the gate leakage and suppresses the surface leakage [19,20].

In this study, we developed a $\mathrm{pH}$ sensor based on an AlGaN/GaN MOS HEMT using the resistive coupling of a coplanar gate structure comprising a control gate (CG) and a sensing gate (SG). Previous AlGaN/GaN MOS HEMT-based ISFETs can easily be damaged, because the HEMT device in these is directly exposed to a chemical solution. To prevent this damage, we designed an AlGaN/GaN MOS HEMT transducer unit that converts biochemical signals into electrical signals and an extended gate (EG) sensing unit that is directly exposed to the $\mathrm{pH}$ solution. This separate structure of the transducer and sensing units fundamentally prevents damage to the expensive HEMT and provides a cost-effective sensor platform by easily replacing the damaged low-cost sensing unit. The variation in the sensitivity of the $\mathrm{pH}$ sensor was evaluated according to the ratio of the series resistance connected to the $\mathrm{CG}\left(\mathrm{R}_{\mathrm{CG}}\right)$ and SG $\left(\mathrm{R}_{\mathrm{SG}}\right)$ of the AlGaN/GaN MOS HEMT transducer, and an amplified sensitivity that exceeded the Nernst limit was obtained. In addition, non-ideal behaviors, such as hysteresis and drift effects, were investigated to verify the stability and reliability of the sensor.

\section{Materials and Methods}

The coplanar gate AlGaN/GaN MOS HEMT transducer unit was fabricated as follows. $\mathrm{AlGaN} / \mathrm{GaN}$ heterostructures were grown in metal organic chemical vapor deposition reactors on (0001) sapphire substrates. A $25 \mathrm{~nm}$ low-temperature GaN nucleation layer was grown on the sapphire substrate, followed by the successive growth of a $1 \mu \mathrm{m}$ highresistance $\mathrm{GaN}$ layer and $1.8 \mu \mathrm{m}$ unintentionally doped $\mathrm{GaN}$ epitaxial layer. Subsequently, a $12 \mathrm{~nm} \mathrm{Al}{ }_{0.25} \mathrm{GaN}$ layer was grown. Mesa separation was realized by etching a $500 \mathrm{~nm}$ $\mathrm{AlGaN} / \mathrm{GaN}$ layer, where the active region was defined by $\mathrm{BCl}_{3}$ - and $\mathrm{Cl}_{2}$ - based inductively coupled plasma etching using a photoresist (PR) mask. A $500 \mathrm{~nm} \mathrm{SiO}$ field oxide layer was deposited via RF magnetron sputtering for a flat surface to avoid breaking of the gate metals at the steep steps in the mesa region. After removing the $\mathrm{PR}$ mask and $\mathrm{SiO}_{2}$ layer from the active region, the $\mathrm{AlGaN} / \mathrm{GaN}$ heterostructure was cleaned using an ammonium sulfide solution with excess sulfur $\left[\left(\mathrm{NH}_{4}\right)_{2} \mathrm{~S}_{x}, 40 \%\right.$ sulfur] to remove the native oxide and prevent the formation of oxide. Subsequently, a $5 \mathrm{~nm} \mathrm{SiO} 2$ layer and $10 \mathrm{~nm} \mathrm{Ta}_{2} \mathrm{O}_{5}$ layer were deposited as gate insulators via RF magnetron sputtering. The source and drain electrodes of Ti/ $\mathrm{Al} / \mathrm{Ni} / \mathrm{Au}(=20 / 100 / 25 / 50 \mathrm{~nm})$ were formed via e-beam evaporator and lift-off, followed by rapid thermal treatment at $800{ }^{\circ} \mathrm{C}$ for $30 \mathrm{~s}$ in $\mathrm{N}_{2}$ ambient. To form series resistors between the HEMT gate (on channel) and the coplanar gates (CG and SG), a $50 \mathrm{~nm}$ indium-tin-oxide (ITO) film with a sheet resistance of $1.7 \times 10^{3} \Omega / \mathrm{sq}$ was deposited. We designed resistors with a width of $2 \mu \mathrm{m}$ and lengths of 10, 20, and $30 \mu \mathrm{m}$ and obtained resistances of 17,34 , and $51 \mathrm{k} \Omega$, respectively. For the HEMT gate and coplanar gate electrodes, $\mathrm{Ni} / \mathrm{Au}(=25 / 100 \mathrm{~nm})$ was deposited via e-beam evaporation and lift-off. Meanwhile, to fabricate the EG sensing unit, a $150 \mathrm{~nm}$ ITO conductive layer and a $50 \mathrm{~nm}$ $\mathrm{SnO}_{2}$ sensing membrane were subsequently deposited on glass substrates via RF magnetron sputtering. Subsequently, a polydimethylsiloxane reservoir was placed on top. Figure 1a,b shows schematics of the coplanar gate AlGaN/GaN MOS HEMT and EG, respectively.

We finally constructed the $\mathrm{pH}$ sensor by connecting the EG to the SG of the AlGaN/GaN MOS HEMT with an electrical cable (Model 5342, Pomana electronics, Everett, WA, USA) to transfer the potential of the $\mathrm{pH}$ solution to the SG. We performed all electrical measurements of device characteristics using an Agilent 4156B precision semiconductor parameter analyzer (Agilent Technologies, Santa Clara, CA, USA). Also, these measure- 
ments were performed in a shielded dark box to prevent external elements such as noise and light. In particular, a commercial $\mathrm{Ag} / \mathrm{AgCl}$ reference electrode (Horiba 2086A-06T, Kyoto, Japan) composed of ceramic-plug junction and internal solution saturated with $\mathrm{KCl}$ and $\mathrm{AgCl}$ was used for $\mathrm{pH}$ sensing.

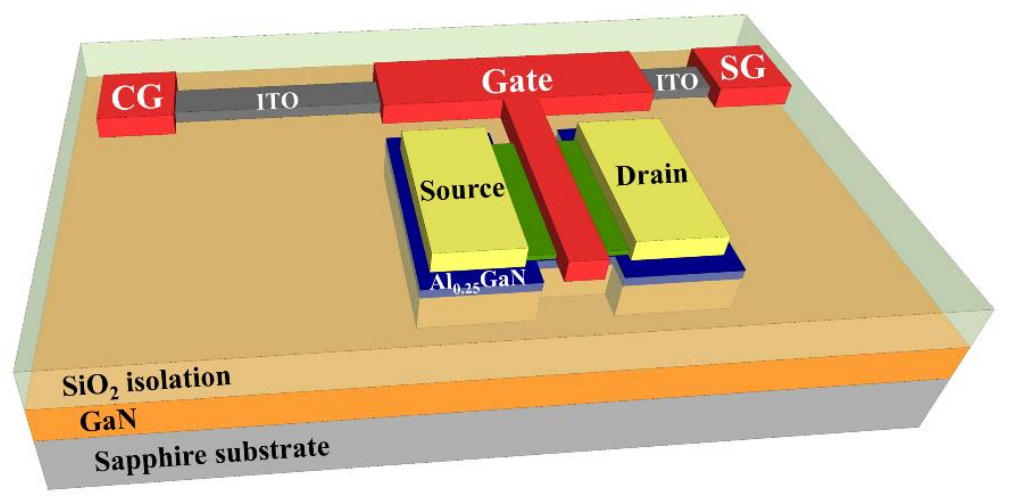

(a)

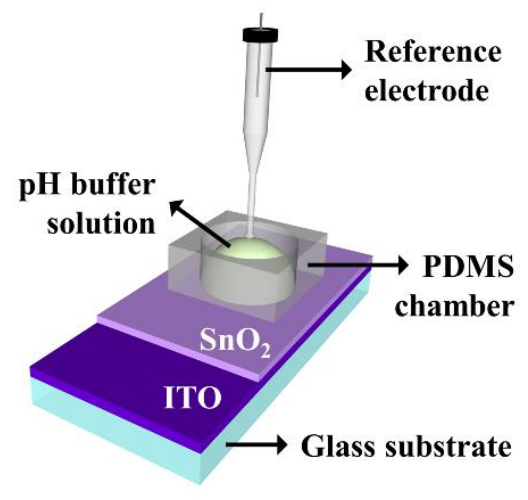

(b)

Figure 1. Schematic of (a) coplanar gate $\mathrm{AlGaN} / \mathrm{GaN}$ metal-oxide-semiconductor high electron mobility transistor (MOS HEMT) transducer unit, and (b) extended gate (EG) sensing unit.

\section{Results}

\subsection{Silvaco TCAD Simulations}

The voltages applied to the CG and SG are denoted as $\mathrm{V}_{\mathrm{CG}}$ and $\mathrm{V}_{\mathrm{SG}}$, respectively. The total resistance $\left(R_{T}\right)$ of a coplanar gate can be expressed as $R_{T}=R_{C G}+R_{S G}$, where $R_{C G}$ and $R_{S G}$ are the resistances of the CG and SG, respectively. Then, the gate voltage $\left(V_{F G}\right)$ of the MOS HEMT is expressed as in Equation (1), and the voltage between CG and SG can be calculated using Equation (2). Eventually, the potential change in $S G\left(\Delta V_{S G}\right)$ is amplified by a factor of $R_{C G} / R_{S G}$, resulting in a voltage change in the $C G\left(\Delta V_{C G}\right)$, which implies that a significantly small change in potential in the SG is amplified by the resistive coupling effect and can be detected in the CG.

$$
\begin{gathered}
\mathrm{V}_{\mathrm{FG}}=\frac{\mathrm{R}_{\mathrm{SG}}}{\mathrm{R}_{\mathrm{T}}} \mathrm{V}_{\mathrm{CG}}+\frac{\mathrm{R}_{\mathrm{CG}}}{\mathrm{R}_{\mathrm{T}}} \mathrm{V}_{\mathrm{SG}}, \\
\mathrm{V}_{\mathrm{CG}}=\frac{\mathrm{R}_{\mathrm{T}}}{\mathrm{R}_{\mathrm{SG}}} \mathrm{V}_{\mathrm{FG}}-\frac{\mathrm{R}_{\mathrm{CG}}}{\mathrm{R}_{\mathrm{SG}}} \mathrm{V}_{\mathrm{SG}}, \\
\therefore \Delta \mathrm{V}_{\mathrm{CG}} \propto \frac{\mathrm{R}_{\mathrm{CG}}}{\mathrm{R}_{\mathrm{SG}}} \Delta \mathrm{V}_{\mathrm{SG}},
\end{gathered}
$$

Figure $2 b$ shows Silvaco TCAD simulations for the transfer characteristic curves of the $\mathrm{AlGaN} / \mathrm{GaN}$ MOS HEMT with $\mathrm{R}_{\mathrm{CG}}: \mathrm{R}_{\mathrm{SG}}=2: 1$. The Silvaco TCAD simulation proposed in this study was to evaluate the signal amplification capability by resistive coupling, and was performed as follows: (1) Atals simulation for MOS HEMT device with conmob (specify concentration dependent mobility model), fldmob (specify lateral electric field-dependent model), SRH (specifies Shockley-Read-Hall recombination). (2) Mixedmode module in Atlas for circuit simulation for resistive coupling between CG and SG. (3) Tunneling conduction such as band-to-band tunneling, Fowler-Nordheim tunneling, direct quantum tunneling, trap assist tunneling, phonon assist electron tunneling, Schottky tunneling, etc. were ignored. As a result, using Equation (3), when $\Delta \mathrm{V}_{S G}$ is $2 \mathrm{~V}, \Delta \mathrm{V}_{\mathrm{CG}}$ is calculated to be $4 \mathrm{~V}$, and the resistance ratio $\mathrm{R}_{\mathrm{CG}} / \mathrm{R}_{\mathrm{SG}}$ is increased to 2 . Figure $2 \mathrm{c}$ shows the dependence of the amplification factor $\left(\Delta \mathrm{V}_{\mathrm{CG}} / \Delta \mathrm{V}_{\mathrm{SG}}\right)$ considering ratios $\mathrm{R}_{\mathrm{CG}}: \mathrm{R}_{\mathrm{SG}}=1: 2,1: 1,2: 1$, and 3:1, where $\Delta \mathrm{V}_{\mathrm{CG}}$ is determined at a drain current of $1 \mathrm{nA}$. The amplification coefficients at ratios $R_{C G}: R_{S G}=1: 2,1: 1,2: 1$, and 3:1 were found to be $0.5,1,2$, and 3, respectively. 


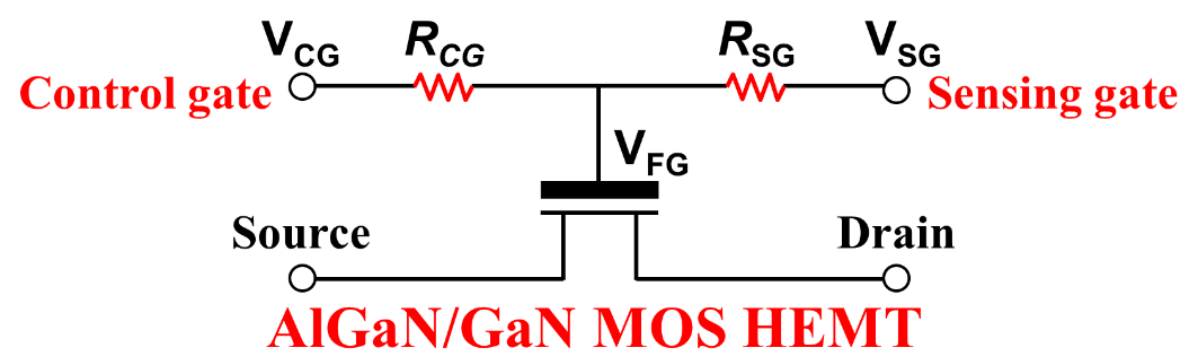

(a)

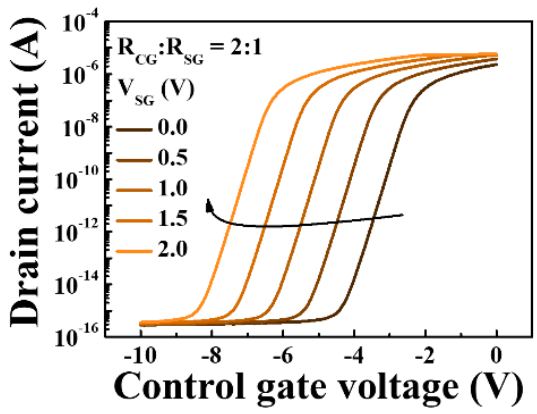

(b)

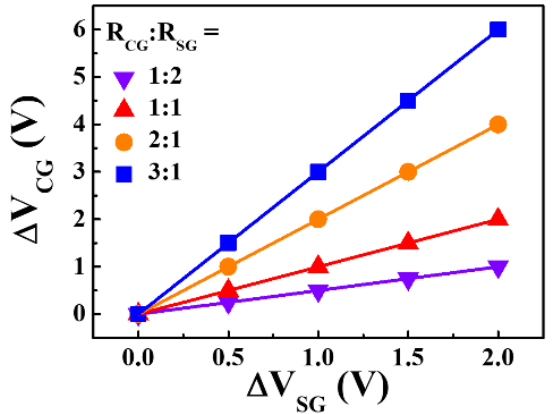

(c)

Figure 2. (a) Simplified equivalent circuit of the $\mathrm{pH}$ sensor based on the coplanar gate AlGaN/GaN MOS HEMT proposed herein. Silvaco TCAD simulation results of (b) transfer characteristic curves shift as a function of $\Delta \mathrm{V}_{\mathrm{SG}}$, and (c) dependence of the amplification factor $\left(\Delta \mathrm{V}_{\mathrm{CG}} / \Delta \mathrm{V}_{\mathrm{SG}}\right)$ on $\mathrm{R}_{\mathrm{CG}}: \mathrm{R}_{\mathrm{SG}}$ of the $\mathrm{pH}$ sensor.

\subsection{Electrical Characteristics of Coplanar Gate AlGaN/GaN MOS HEMT}

Figure 3 a shows the transfer characteristic curves of the fabricated coplanar gate $\mathrm{AlGaN} / \mathrm{GaN}$ MOS HEMT. Here, the threshold voltage is $-0.99 \mathrm{~V}$, electron concentration is $7.47 \times 10^{12} \mathrm{~cm}^{-2}$, electron mobility is $2835.9 \mathrm{~cm}^{2} / \mathrm{V} \mathrm{s}$, on/off current ratio is $5.55 \times 10^{8}$, and subthreshold swing is $79.08 \mathrm{mV} / \mathrm{dec}$. A low gate leakage current was observed because the $\mathrm{SiO}_{2} / \mathrm{Ta}_{2} \mathrm{O}_{5}$ stacked gate insulator effectively blocked the gate leakage and suppressed the surface leakage. In addition, the output characteristic curves in Figure $3 \mathrm{~b}$ indicate a high drain drive current due to the high electron concentration and mobility of the AlGaN/GaN MOS HEMT.

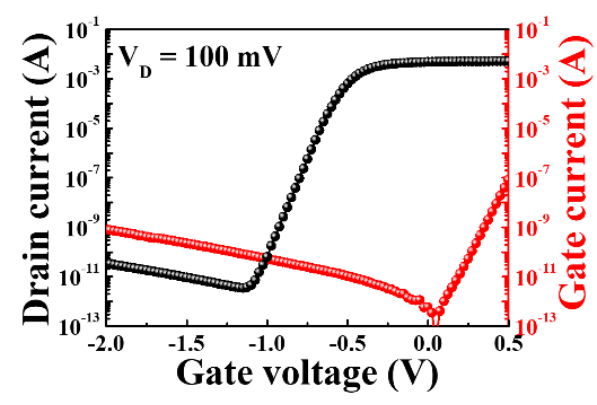

(a)

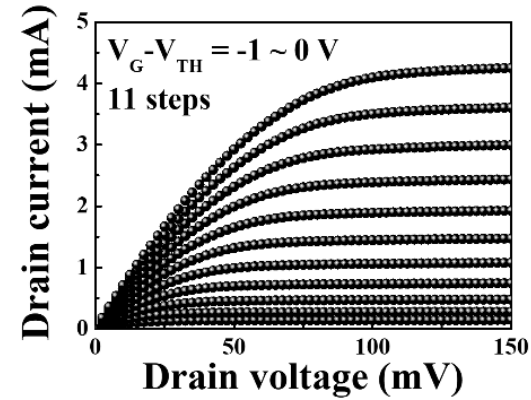

(b)

Figure 3. (a) Transfer characteristics and (b) output characteristic curves of the fabricated AlGaN/GaN MOS HEMT.

\section{3. pH Sensing Characteristics of Coplanar Gate AlGaN/GaN MOS HEMT}

There is a Nernst limit for $\mathrm{pH}$ sensing properties that cannot exceed $59.14 \mathrm{mV} / \mathrm{pH}$ according to site-binding theory. In the site-binding theory, the ability to detect ions depends entirely on the surface potential $(\psi)$, which is summarized in the Equation $(4):[21,22]$ 


$$
\psi=2.303 \frac{k T}{q} \frac{\beta}{\beta+1}\left(p H_{p z c}-p H\right),
$$

where $k$ is Boltzmann constant, $T$ is the absolute temperature, $q$ is the elementary charge, $p H_{p z c}$ is the $\mathrm{pH}$ at the point of zero charge, and $\beta$ is a parameter that denotes the chemical sensitivity of the sensing membrane. The $\psi$ depends on the properties of the sensing membrane and the $\mathrm{pH}$ level of the electrolyte. Thus, the shift of the threshold voltage $\left(\Delta \mathrm{V}_{\mathrm{TH}}\right)$ for the transistor is determined by $\Delta \psi$. Based on the simulation result, when resistive coupling is introduced, $\Delta \mathrm{V}_{\mathrm{TH}}$ becomes $\mathrm{R}_{\mathrm{CG}} / \mathrm{R}_{\mathrm{SG}}$ times $\Delta \psi$, which can amplify the sensitivity.

Figure $4 \mathrm{a}-\mathrm{c}$ shows the transfer characteristic curves of the $\mathrm{pH}$ sensor for the ratios $\mathrm{R}_{\mathrm{CG}}: \mathrm{R}_{\mathrm{SG}}=1: 1,2: 1$, and 3:1, respectively. We measured the sensing properties using buffer solutions with the following $\mathrm{pH}$ concentrations: 3.07, 4.08, 5.99, 6.95, 8.97, and 9.87. From Figure 4 , it can be seen that as the $\mathrm{pH}$ value increases, the transfer characteristic curve shifts in the positive voltage direction. Figure $4 \mathrm{~d}$ shows a plot of $\Delta \mathrm{V}_{\mathrm{CG}}$ as a function of the $\mathrm{pH}$ value. Here, $\Delta \mathrm{V}_{\mathrm{CG}}$ is defined as the shift of the $\mathrm{V}_{\mathrm{CG}}$ extracted from the drain current of $1 \mathrm{nA}$, corresponding to the $\mathrm{pH}$ sensitivity as a function of the concentration of the buffer solution. For $\mathrm{R}_{\mathrm{CG}}: \mathrm{R}_{\mathrm{SG}}=1: 1$, the $\mathrm{pH}$ sensitivity is $56.63 \mathrm{mV} / \mathrm{pH}$, which is lower than the Nernst limit of $59.14 \mathrm{mV} / \mathrm{pH}$. However, for $\mathrm{R}_{\mathrm{CG}}: \mathrm{R}_{\mathrm{SG}}=2: 1$ and 3:1, the $\mathrm{pH}$ sensitivities are 112.17 and $167.71 \mathrm{mV} / \mathrm{pH}$, respectively, which are amplified by a factor of $R_{\mathrm{CG}} / \mathrm{R}_{\mathrm{SG}}$ and exceed the Nernst limit. In addition, the linear fitting line for extracting the sensitivity in Figure $4 \mathrm{~d}$ showed more than $99.8 \%$ linearity in $\mathrm{R}_{\mathrm{CG}}: \mathrm{R}_{\mathrm{SG}}=1: 1,2: 1$, and 3:1. Figure $4 \mathrm{~d}$ also shows the deviation for 20 measurements at each $\mathrm{pH}$ value, indicating reliable sensing performance. This means that there is no Debye screening length limit for the various $\mathrm{pH}$ buffer solutions used in this study.

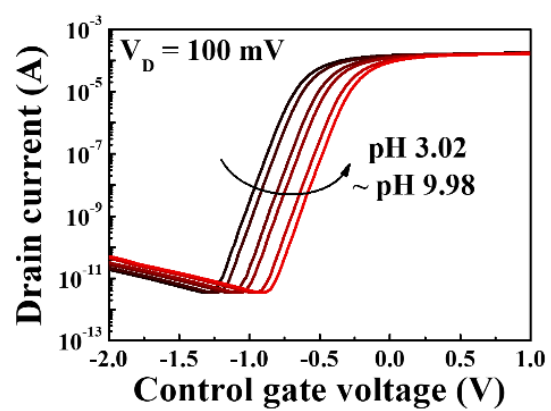

(a)

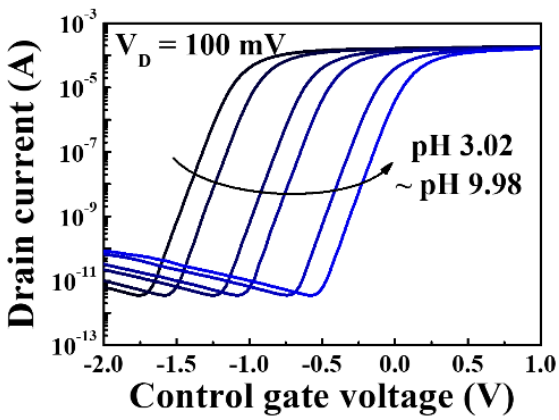

(c)

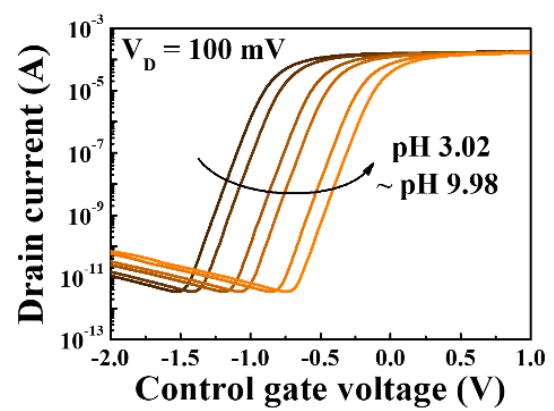

(b)

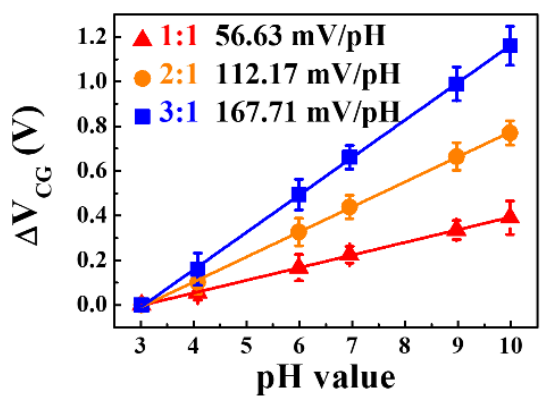

(d)

Figure 4. Transfer characteristic curves of the $\mathrm{pH}$ sensor based on a coplanar gate AlGaN/GaN MOS HEMT for $\mathrm{R}_{\mathrm{CG}}: \mathrm{R}_{\mathrm{SG}}=(\mathbf{a}) 1: 1$, (b) 2:1, and (c) 3:1. (d) $\Delta \mathrm{V}_{\mathrm{CG}}$ as a function of the $\mathrm{pH}$ value.

Reliability-related hysteresis effects are due to the presence of slowly reacting $\mathrm{OH}$-sites on the surface of the sensing membrane and the transport of certain species in the bulk of the sensing membrane [23-25]. Meanwhile, stability-related drift effects are due to the hopping and/or trap-limited transport of $\mathrm{OH}$-related species from the electrolyte and defects present 
in the sensing membrane [26,27]. These non-ideal behaviors limit the accuracy of the sensor. Figure 5a shows the hysteresis characteristics when the $\mathrm{pH}$ is changed as follows: $7 \rightarrow 10 \rightarrow 7$ $\rightarrow 4 \rightarrow 7$. It can be seen that, for $\mathrm{R}_{\mathrm{CG}}: \mathrm{R}_{\mathrm{SG}}=1: 1,2: 1$, and 3:1, the hysteresis voltages are 1.8 , 3.5 , and $7.1 \mathrm{mV}$, respectively. Figure $5 \mathrm{~b}$ shows the drift rates upon exposure to a $\mathrm{pH} 7 \mathrm{buffer}$ solution for $10 \mathrm{~h}$. It can be seen that, for $\mathrm{R}_{\mathrm{CG}}: \mathrm{R}_{\mathrm{SG}}=1: 1,2: 1$, and $3: 1$, the drift rates are $0.4,0.6$, and $0.7 \mathrm{mV} / \mathrm{h}$, respectively.

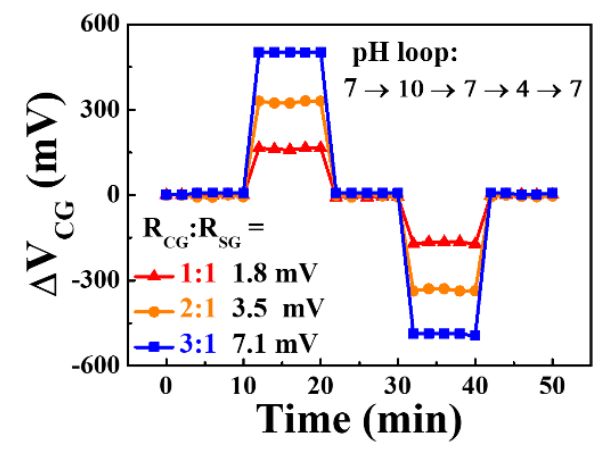

(a)

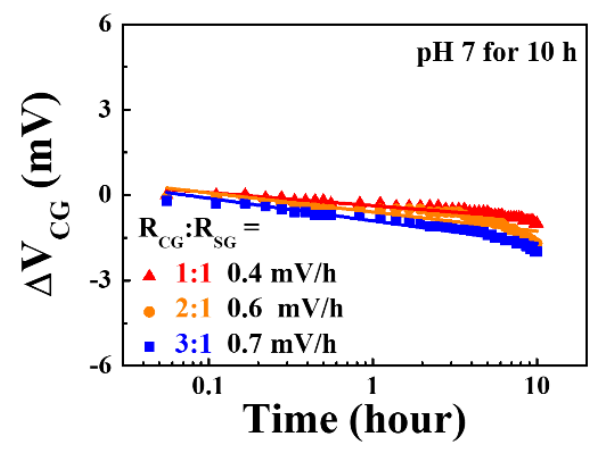

(b)

Figure 5. (a) Hysteresis effect and (b) drift effect of the $\mathrm{pH}$ sensor based on a coplanar gate AlGaN/GaN MOS HEMT for $\mathrm{R}_{\mathrm{CG}}: \mathrm{R}_{\mathrm{SG}}=1: 1,2: 1$, and $3: 1$.

\section{Conclusions}

We developed a pH sensor based on a coplanar gate AlGaN/GaN MOS HEMT with increased sensitivity using the resistive coupling effect. Through Silvaco TCAD simulations, the $\mathrm{pH}$ sensitivity amplification corresponding to the ratio of the series resistance connected to the $C G$ and $S G\left(R_{C G} / R_{S G}\right)$ is predicted. The $\mathrm{pH}$ sensitivity of the fabricated sensors increases proportionally with $R_{C G} / R_{S G}$. In particular, for $R_{C G}: R_{S G}=2: 1$ and 3:1, the sensitivity was 112.17 and $167.71 \mathrm{mV} / \mathrm{pH}$, respectively, which are greater than the Nernst limit. We also verified the stability and reliability of the sensor by evaluating its nonideal behaviors, such as the hysteresis and drift effects. In addition, by applying the disposable EG sensing unit, damage to the AlGaN/GaN MOS HEMT transducer unit due to chemical solutions was prevented. The results of this study indicate that the $\mathrm{pH}$ sensor developed has high performance, stability, and reliability and is also disposable. Thus, since the sensor proposed in this study is based on a HEMT device, it is expected to be suitable for integration with wide transmission bandwidth, high temperature, speed and frequency power electronics. In addition, the $\mathrm{pH}$ sensor proposed in this study detects the potential change of the sensing membrane using EG. Therefore, when the coplanar gate $\mathrm{AlGaN} / \mathrm{GaN}$ MOS HEMT proposed in this study is introduced into the subsequent study on EG, various biological events such as enzyme-substrate reactions, antigen-antibody binding, and nucleic acid hybridization can be detected with high sensitivity.

Author Contributions: S.-K.C.: conceptualization, formal analysis, methodology, investigation, data curation, visualization, software, resources, writing - original draft. W.-J.C.: conceptualization, methodology, investigation, resources, formal analysis, funding acquisition, supervision, validation, writing - review and editing. All authors have read and agreed to the published version of the manuscript.

Funding: The present research has been conducted by the Research Grant of Kwangwoon University in 2020, and this work was supported by the National Research Foundation of Korea (NRF) grant funded by the Korea government (MSIT) (No. 2020R1A2C1007586). This research was funded and conducted under the Competency Development Program for Industry Specialists of the Korean Ministry of Trade, Industry and Energy (MOTIE), operated by Korea Institute for Advancement of Technology (KIAT) (No. P0002397, HRD program for Industrial Convergence of Wearable Smart Devices).

Conflicts of Interest: The authors declare no conflict of interest. 


\section{References}

1. Bergveld, P. Development of an Ion-Sensitive Solid-State Device for Neurophysiological Measurements. IEEE Trans. Biomed. Eng. 1970, 17, 70-71. [CrossRef]

2. Bergveld, P. Thirty years of ISFETOLOGY: What happened in the past 30 years and what may happen in the next 30 years. Sens. Actuators B Chem. 2003, 88, 1-20. [CrossRef]

3. Knopfmacher, O.; Tarasov, A.; Fu, W.; Wipf, M.; Niesen, B.; Calame, M.; Schoönenberger, C. Nernst Limit in Dual-Gated Si-Nanowire FET Sensors. Nano Lett. 2010, 10, 2268-2274. [CrossRef]

4. Spijkman, M.; Smits, E.C.P.; Cillessen, J.F.M.; Biscarini, F.; Blom, P.W.M.; De Leeuw, D.M. Beyond the Nernst-limit with dual-gate ZnO ion-sensitive field-effect transistors. Appl. Phys. Lett. 2011, 98, 043502. [CrossRef]

5. Spijkman, M.-J.; Myny, K.; Smits, E.C.P.; Heremans, P.; Blom, P.W.M.; De Leeuw, D.M. Dual-Gate Thin-Film Transistors, Integrated Circuits and Sensors. Adv. Mater. 2011, 23, 3231-3242. [CrossRef] [PubMed]

6. Lim, H.K.; Fossum, J.G. Threshold voltage of thin-film silicon-on-insulator (SOI) MOSFET's. IEEE Trans. Electron. Devices 1983, 30, 1244-1251.

7. Jang, H.J.; Cho, W.J. Performance enhancement of capacitive-coupling dual-gate ion-sensitive field-effect transistor in ultra-thinbody. Sci. Rep. 2014, 4, 5284. [CrossRef]

8. Lee, I.-K.; Lee, K.H.; Lee, S.; Cho, W.-J. Microwave Annealing Effect for Highly Reliable Biosensor: Dual-Gate Ion-Sensitive Field-Effect Transistor Using Amorphous InGaZnO Thin-Film Transistor. ACS Appl. Mater. Interfaces 2014, 6, 22680-22686. [CrossRef]

9. Jeon, J.-H.; Cho, W.-J. Ultrasensitive Coplanar Dual-Gate ISFETs for Point-of-Care Biomedical Applications. ACS Omega 2020, 5, 12809-12815. [CrossRef]

10. Ambacher, O.; Smart, J.; Shealy, J.R.; Weimann, N.G.; Chu, K.; Murphy, M.; Schaff, W.J.; Eastman, L.F.; Dimitrov, R.; Wittmer, L.; et al. Two-dimensional electron gases induced by spontaneous and piezoe-lectric polarization charges in $\mathrm{N}$-and $\mathrm{Ga}$-face AlGaN/GaN heterostructures. J. Appl. Phys. 1999, 85, 1999. [CrossRef]

11. Sarangadharan, I.; Regmi, A.; Chen, Y.-W.; Hsu, C.-P.; Chen, P.-C.; Chang, W.-H.; Lee, G.-Y.; Chyi, J.-I.; Shiesh, S.-C.; Lee, G.-B.; et al. High sensitivity cardiac troponin I detection in physiological environment using AlGaN/GaN High Electron Mobility Transistor (HEMT) Biosensors. Biosens. Bioelectron. 2018, 100, 282-289. [CrossRef] [PubMed]

12. Espinosa, N.; Schwarz, S.U.; Cimalla, V.; Ambacher, O. Detection of different target-DNA concentrations with highly sensitive AlGaN/GaN high electron mobility transistors. Sens. Actuators B Chem. 2015, 210, 633-639. [CrossRef]

13. Li, J.-D.; Cheng, J.-J.; Miao, B.; Wei, X.-W.; Xie, J.; Zhang, J.-C.; Zhang, Z.-Q.; Li, H.-W.; Wu, D.-M. Label free electrical detection of prostate specific antigen with millimeter grade biomolecule-gated AlGaN/GaN high electron mobility transistors. Microsyst. Technol. 2014, 21, 1489-1494. [CrossRef]

14. Li, J.-D.; Cheng, J.-J.; Miao, B.; Wei, X.-W.; Xie, J.; Zhang, J.-C.; Zhang, Z.-Q.; Wu, D.-M. Detection of prostate-specific antigen with biomolecule-gated AlGaN/GaN high electron mobility transistors. J. Micromech. Microeng. 2014, 24, 75023. [CrossRef]

15. Lee, C.T.; Chiu, Y.S. Photoelectrochemical passivated ZnO-based nanorod structured glucose biosensors using gate-recessed $\mathrm{AlGaN} / \mathrm{GaN}$ ion-sensitive field-effect-transistors. Sens. Actuators B Chem. 2015, 210, 756-761. [CrossRef]

16. Chu, B.H.; Kang, B.S.; Hung, S.C.; Chen, K.H.; Ren, F.; Sciullo, A.; Gila, B.P.; Pearton, S.J. Aluminum Gallium Nitride (GaN)/GaN High Electron Mobility Transistor-Based Sensors for Glucose Detection in Exhaled Breath Condensate. J. Diabetes Sci. Technol. 2010, 4, 171-179. [CrossRef]

17. Pulikkathodi, A.K.; Sarangadharan, I.; Hsu, C.-P.; Chen, Y.-H.; Hung, L.-Y.; Lee, G.-Y.; Chyi, J.-I.; Lee, G.-B.; Wang, Y.-L. Enumeration of circulating tumor cells and investigation of cellular responses using aptamer-immobilized AlGaN/GaN high electron mobility transistor sensor array. Sens. Actuators B Chem. 2018, 257, 96-104. [CrossRef]

18. Jung, S.; Baik, K.H.; Ren, F.; Pearton, S.J.; Jang, S. Pt-AlGaN/GaN hydrogen sensor with water-blocking PMMA layer. IEEE Electron Device Lett. 2017, 38, 657-660. [CrossRef]

19. Lee, C.S.; Liao, Y.H.; Chou, B.Y.; Liu, H.Y.; Hsu, W.C. Composite $\mathrm{HfO}_{2} / \mathrm{Al}_{2} \mathrm{O}_{3}$-dielectric $\mathrm{AlGaAs} / \mathrm{InGaAs} \mathrm{MOS}-\mathrm{HEMTs}$ by using RF sputtering/ozone water oxidation. Superlattices Microstruct. 2014, 72, 194-203. [CrossRef]

20. Seok, O.; Ahn, W.; Han, M.-K.; Ha, M.-W. High on/off current ratio AlGaN/GaN MOS-HEMTs employing RF-sputtered HfO 2 gate insulators. Semicond. Sci. Technol. 2013, 28, 025001. [CrossRef]

21. Pan, T.-M.; Huang, M.-D.; Lin, C.-W.; Wu, M.-H. Development of high- $\mathrm{K} \mathrm{HoTiO}_{3}$ sensing membrane for $\mathrm{pH}$ detection and glucose biosensing. Sens. Actuators B Chem. 2010, 144, 139-145. [CrossRef]

22. Chou, J.-C.; Liao, L.P. Study on $\mathrm{pH}$ at the point of zero charge of $\mathrm{TiO}_{2} \mathrm{pH}$ ion-sensitive field effect transistor made by the sputtering method. Thin Solid Films 2005, 476, 157-161. [CrossRef]

23. Chang, S.P.; Yang, T.H. Sensing performance of EGFET pH sensors with CuO nanowires fabricated on glass substrate. Int. J. Electrochem. Sci. 2012, 7, 5020-5027.

24. Gandhi, O.P.; Chen, J.-Y.; Riazi, A. Currents Induced in a Human Being for Plane-Wave Exposure Conditions 0-50 MHz and for RF Sealers. IEEE Trans. Biomed. Eng. 1986, 33, 757-767. [CrossRef] [PubMed]

25. Bousse, L.; Mostarshed, S.; van der Schoot, B.; De Rooij, N.F. Comparison of the hysteresis of $\mathrm{Ta}_{2} \mathrm{O}_{5}$ and $\mathrm{Si}_{3} \mathrm{~N}_{4} \mathrm{pH}-\mathrm{sensing}$ insulators. Sens. Actuators B Chem. 1994, 17, 157-164. [CrossRef]

26. Bousse, L.; Bergveld, P. The role of buried OH sites in the response mechanism of inorganic-gate pH-sensitive ISFETs. Sens. Actuators 1984, 6, 65-78. [CrossRef]

27. Jamasb, S.; Collins, S.; Smith, R.L. A physical model for drift in pH ISFETs. Sens. Actuators B Chem. 1998, 49, 146-155. [CrossRef] 